\title{
LIXIVIAÇÃO DE CHUMBO E ZINCO EM SOLO TRATADO COM RESÍDUOS DE SIDERURGIA ${ }^{1}$
}

\author{
Robervone Severina de Melo Pereira do Nascimento², \\ Geila Santos Carvalho ${ }^{3}$, Leônidas Paixão Passos ${ }^{4}$, João José Marques ${ }^{3}$
}

\begin{abstract}
LEAD AND ZINC LEACHING IN SOIL TREATED WITH IRON SMELTING RESIDUES

In order to evaluate the dynamics of $\mathrm{Zn}$ and $\mathrm{Pb}$ in the soil, a greenhouse experiment was set up in pots filled with soil samples (Typic Hapludox) treated with increasing doses of iron smelting residues. It was set under a completely randomized design, in a $3 \times 5$ factorial scheme, with three replications, combining three iron smelting residues (mill scale, filter press mud, and phosphate mud), with five doses for each residue $\left(0 \mathrm{t} \mathrm{ha}^{-1}, 1 \mathrm{t} \mathrm{ha}^{-1}, 2 \mathrm{t} \mathrm{ha} \mathrm{a}^{-1}, 4 \mathrm{tha}^{-1}\right.$, and $\left.8 \mathrm{t} \mathrm{ha}^{-1}\right)$. Elephant grass was cultivated during 120 days, followed by common beans, for 75 days. In that period, contents of $\mathrm{Zn}$ and $\mathrm{Pb}$ were determined in the leachate. $\mathrm{No} \mathrm{Pb}$ was found in the leachate, but $\mathrm{Zn}$ proved to be quite mobile in this soil. In soils treated with mill scale and filter press mud, no risk of groundwater contamination was observed, however, the $8 \mathrm{t} \mathrm{ha}^{-1}$ phosphate mud rate increased $\mathrm{Zn}$ contents in the leachate above the maximum allowed by environmental regulations. This fact limits the use of such residue for agricultural purposes. The other two residues should be evaluated in field-scale tests aiming their agricultural use.
\end{abstract}

KEY-WORDS: Industrial residue; heavy metal; mill scale; filter press mud; phosphate mud.

\section{INTRODUÇÃO}

Embora o consumo per capita de aço seja relativamente baixo no Brasil, com o crescimento da economia, sua produção pode crescer ainda mais, aumentando a geração de resíduos (Prado et al. 2001). Os principais resíduos do processo siderúrgico são escórias, carepas e lamas de alto-forno e de aciaria e os finos de carvão e minério. No ano de 2003, a indústria do aço produziu 13,5 milhões de toneladas de resíduos, com média de $435 \mathrm{~kg}$ de resíduo por tonelada de aço produzido (Cunha et al. 2006).

\section{RESUMO}

\begin{abstract}
Objetivou-se, com este estudo, avaliar a mobilidade de $\mathrm{Pb}$ e $\mathrm{Zn}$ no solo. Instalou-se um experimento, em casa-de-vegetação, em vasos preenchidos com amostras de Latossolo Vermelho-Amarelo, submetidas a doses de resíduos siderúrgicos, sob delineamento inteiramente casualizado, em esquema fatorial $3 \times 5$, com três repetições, combinando-se três resíduos siderúrgicos (carepa de aciaria, lama de filtro-prensa e lama de fosfato), com cinco doses de cada resíduo $\left(0 \mathrm{tha}^{-1}, 1 \mathrm{t} \mathrm{ha}^{-1}, 2 \mathrm{tha} \mathrm{h}^{-1}, 4 \mathrm{tha} \mathrm{ha}^{-1} \mathrm{e} 8 \mathrm{tha}^{-1}\right)$. Cultivou-se capim-elefante, por 120 dias, e, posteriormente, realizou-se o cultivo de feijão, durante 75 dias. Neste período, avaliaram-se as concentrações de $\mathrm{Pb}$ e $\mathrm{Zn}$ no lixiviado. Não houve lixiviação de $\mathrm{Pb}$, porém, o $\mathrm{Zn}$ apresentou bastante mobilidade na coluna de solo. Em solo adubado com carepa de aciaria e lama de filtro-prensa, não foram observados riscos de contaminação do lençol freático por $\mathrm{Zn}$ e $\mathrm{Pb}$, entretanto, a dose de $8 \mathrm{tha}^{-1}$ de lama de fosfato elevou os teores de Zn no lixiviado acima do máximo permitido pela legislação. Tal fato limita o uso deste último resíduo em doses altas. Os demais resíduos (carepa de aciaria e lama de filtro-prensa) devem ser testados em experimentos de campo, visando à sua possível utilização agrícola.
\end{abstract}

PALAVRAS-CHAVE: Resíduo industrial; metal pesado; carepa de aciaria; lama de filtro-prensa; lama de fosfato.

Uma opção de destino para estes resíduos é sua utilização na agricultura, pois podem melhorar as propriedades físicas e químicas do solo e aumentar a atividade biológica do mesmo, além de contribuir para a reciclagem de nutrientes (Prado et al. 2001). No entanto, o resíduo siderúrgico praticamente não é utilizado na agricultura brasileira, contrariamente ao que ocorre em outros países, como o Japão. Isto se deve, entre outros fatores, aos poucos dados experimentais obtidos no Brasil (Prado et al. 2002). Para o uso seguro de resíduos do processo siderúrgico na agricultura, deve-se considerar a presença de metais

1. Trabalho recebido em nov./2009 e aceito para publicação em dez./2010 (nº registro: PAT 8089/ DOI: 10.5216/pat.v40i4.8089).

2. Instituto Nacional de Colonização e Reforma Agrária (INCRA), Brasília, DF, Brasil.

E-mail: robervone.nascimento@incra.gov.br.

3. Universidade Federal de Lavras, Departamento de Ciência do Solo, Lavras, MG, Brasil.

E-mails: geilacarvalho@yahoo.com.br,jmarques@ufla.br.

4. Embrapa Gado de Leite, Juiz de Fora, MG, Brasil.E-mail: lpassos@cnpgl.embrapa.br. 
pesados potencialmente tóxicos em sua composição, sendo o $\mathrm{Cd}, \mathrm{Cu}, \mathrm{Zn}$ e $\mathrm{Pb}$ os mais perigosos, devido à sua toxicidade e potencial de bioacumulação (Maeda et al. 1990). Embora Cu e Zn sejam micronutrientes para as plantas, dependendo da dose, podem tornar-se tóxicos e ocasionar contaminação ao meio ambiente. Sabe-se, também, que as concentrações destes elementos nos resíduos siderúrgicos podem variar, em função do tipo de resíduo e do processo adotado pela indústria (Prado et al. 2001).

Os metais pesados podem expressar seu potencial poluente diretamente sobre os organismos do solo, pela disponibilidade às plantas e contaminação de águas superficiais, via erosão do solo, e de águas subsuperficiais, por movimentação vertical descendente no perfil do solo (Oliveira et al. 2002). A possível contaminação por metais pesados, em aquíferos próximos a áreas de deposição de resíduos siderúrgicos, dependerá, dentre numerosos fatores, da concentração e solubilidade destes elementos presentes nos resíduos, da quantidade de resíduos aplicada, da precipitação pluviométrica e de sua interação com a fase sólida do solo (Amaral Sobrinho et al. 1998). Esta interação é bastante complexa, envolvendo reações de adsorção e dessorção, precipitação e dissolução, complexação e oxiredução (Amaral Sobrinho et al. 1998).

Estudos sobre a mobilidade de metais pesados no solo têm demonstrado que $\mathrm{Pb}, \mathrm{Cr}$ e $\mathrm{Cu}$ apresentam baixa mobilidade, acumulando-se na superfície de solos contaminados. Por outro lado, $\mathrm{Zn}, \mathrm{Mn}, \mathrm{Ni}$ e, principalmente, $\mathrm{Cd}$ são mais móveis no perfil do solo, representando maior risco de contaminação da água subterrânea. Muitas formas tóxicas dos metais catiônicos apresentam baixa mobilidade no solo, por formarem fortes complexos de esfera interna com os minerais (Hayes \& Traina 1998). Esta capacidade de formar complexos limita a toxicidade de alguns metais pesados, podendo, também, torná-los menos disponíveis no solo, pois as reações com os minerais passam a prevalecer.

Em solos de regiões tropicais, existem muitas dúvidas a respeito da mobilidade dos metais pesados, justificadas, em parte, pela carência de estudos a longo prazo, agravada pela tendência de grande mobilidade destes metais, já que, nestas regiões, predominam solos altamente intemperizados, sob regimes de temperatura e precipitações pluviais elevadas.

Diante do exposto, objetivou-se avaliar, em vasos, sob condições de casa-de-vegetação, a mobi- lidade de $\mathrm{Pb}$ e $\mathrm{Zn}$, provenientes de resíduos siderúrgicos do município de Juiz de Fora (MG), em Latossolo Vermelho-Amarelo distrófico típico, cultivado com capim-elefante e feijão.

\section{MATERIAL E MÉTODOS}

O experimento foi realizado de agosto de 2003 a fevereiro de 2004, em casa-de-vegetação do Departamento de Ciência do Solo da Universidade Federal de Lavras, em Lavras (MG). Utilizou-se a camada superficial (0-0,2 m) de um Latossolo Vermelho-Amarelo distrófico típico argiloso A moderado, coletado no município de Juiz de Fora (MG), o qual foi caracterizado física e quimicamente (Tabela 1). O solo havia sido cultivado com capim-elefante há mais de 10 anos, sem receber adubação nos últimos cinco anos, mas tendo sido adubado anteriormente, tornando-se epieutrófico.

Tabela 1. Propriedades químicas e físicas do solo utilizado no experimento (Lavras, MG, 2003).

\begin{tabular}{|c|c|}
\hline Atributos & Valores \\
\hline $\mathrm{pH} \mathrm{H}_{2} \mathrm{O}(1: 2,5)$ & 5,9 \\
\hline $\mathrm{P}\left(\mathrm{mg} \mathrm{dm}^{-3}\right)^{(1)}$ & 8 \\
\hline $\mathrm{K}\left(\mathrm{mg} \mathrm{dm}^{-3}\right)^{(1)}$ & 44 \\
\hline $\mathrm{Ca}^{2+}\left(\mathrm{cmol}_{\mathrm{c}} \mathrm{dm}^{-3}\right)^{(2)}$ & 4 \\
\hline $\mathrm{Mg}^{2+}\left(\mathrm{cmol}_{\mathrm{c}} \mathrm{dm}^{-3}\right)^{(2)}$ & 2 \\
\hline $\mathrm{Al}^{3+}\left(\mathrm{cmol}_{\mathrm{c}} \mathrm{dm}^{-3}\right)^{(2)}$ & 0 \\
\hline $\mathrm{H}+\mathrm{Al}\left(\mathrm{cmol}_{\mathrm{c}} \mathrm{dm}^{-3}\right)^{(3)}$ & 3 \\
\hline CTC efetiva $\left(\mathrm{cmol}_{\mathrm{c}} \mathrm{dm}^{-3}\right)$ & 6,11 \\
\hline CTC a pH $7\left(\mathrm{cmol}_{\mathrm{c}} \mathrm{dm}^{-3}\right)$ & 9,11 \\
\hline Saturação por bases (\%) & 62 \\
\hline Saturação por alumínio (\%) & 0 \\
\hline $\left.\mathrm{Cu}(\mathrm{mg} \mathrm{dm})^{-3}\right)^{(1)}$ & 3 \\
\hline $\mathrm{Cu}\left(\mathrm{mg} \mathrm{dm}^{-3}\right)^{(6)}$ & 20 \\
\hline $\mathrm{Fe}\left(\mathrm{mg} \mathrm{dm}^{-3}\right)^{(1)}$ & 228 \\
\hline $\mathrm{Fe}\left(\mathrm{mg} \mathrm{dm} \mathrm{m}^{-3}\right)^{(6)}$ & 42.238 \\
\hline $\operatorname{Mn}\left(\mathrm{mg} \mathrm{dm}^{-3}\right)^{(1)}$ & 34 \\
\hline $\operatorname{Mn}\left(\mathrm{mg} \mathrm{dm}^{-3}\right)^{(6)}$ & 67 \\
\hline $\mathrm{Zn}\left(\mathrm{mg} \mathrm{dm}^{-3}\right)^{(1)}$ & 5 \\
\hline $\mathrm{Zn}\left(\mathrm{mg} \mathrm{dm}^{-3}\right)^{(6)}$ & 20 \\
\hline $\mathrm{Ni}\left(\mathrm{mg} \mathrm{dm}^{-3}\right)^{(1)}$ & 1 \\
\hline $\mathrm{Ni}\left(\mathrm{mg} \mathrm{dm}^{-3}\right)^{(6)}$ & 8 \\
\hline $\mathrm{Pb}\left(\mathrm{mg} \mathrm{dm}^{-3}\right)^{(1)}$ & 2 \\
\hline $\mathrm{Pb}\left(\mathrm{mg} \mathrm{dm}^{-3}\right)^{(6)}$ & 14 \\
\hline $\mathrm{Cd}\left(\mathrm{mg} \mathrm{dm}^{-3}\right)^{(1)}$ & 0,2 \\
\hline $\mathrm{Cd}\left(\mathrm{mg} \mathrm{dm}^{-3}\right)^{(6)}$ & 0,2 \\
\hline $\mathrm{Cr}\left(\mathrm{mg} \mathrm{dm}^{-3}\right)^{(1)}$ & 0,2 \\
\hline $\left.\mathrm{Cr}(\mathrm{mg} \mathrm{dm})^{-3}\right)^{(6)}$ & 74 \\
\hline Carbono orgânico $\left(\text { dag kg }^{-1}\right)^{(4)}$ & 1,9 \\
\hline Areia $\left(\mathrm{g} \mathrm{kg}^{-1}\right)^{(5)}$ & 380 \\
\hline Silte $\left(\mathrm{g} \mathrm{kg}^{-1}\right)^{(5)}$ & 160 \\
\hline Argila $\left(\mathrm{g} \mathrm{kg}^{-1}\right)^{(5)}$ & 460 \\
\hline
\end{tabular}


Os resíduos estudados foram carepa de aciaria (CA), lama de fosfato (LF) e lama de filtro-prensa (LFP), coletados em indústria representativa de grande porte em Juiz de Fora (MG).

Uma amostra de cada resíduo foi coletada para determinação de macro e micronutrientes e metais pesados, de acordo com o método USEPA 3051A (USEPA 1998). Neste método, cerca de $1 \mathrm{~g}$ de resíduo foi digerido em $10 \mathrm{~mL}$ de $\mathrm{HNO}_{3}$ concentrado, em frascos de Teflon ${ }^{\circledR}$ hermeticamente fechados, aquecidos em forno de micro-ondas, por 10 minutos. Os elementos analisados foram: $\mathrm{P}, \mathrm{S}, \mathrm{Mg}, \mathrm{K}, \mathrm{Ca}$, $\mathrm{Cr}, \mathrm{Mn}, \mathrm{Fe}, \mathrm{Ni}, \mathrm{Cu}, \mathrm{Zn}, \mathrm{Cd}$ e Pb (Tabela 2). O P foi determinado por colorimetria, o $\mathrm{S}$ por turbidimetria, o K em fotômetro de chama (Malavolta et al. 1989) e os demais elementos foram determinados em espectrofotômetro de absorção atômica, em chama de ar-acetileno. Os resíduos apresentaram ampla distribuição dos elementos de interesse. A carepa de aciaria apresentou o menor teor de $\mathrm{Pb}$ e $\mathrm{Zn}$. A lama de fosfato apresentou o maior teor de $\mathrm{Zn}$ e a lama de filtro-prensa o maior teor de $\mathrm{Pb}$.

$\mathrm{O}$ delineamento experimental foi inteiramente casualizado, com três repetições, em esquema fatorial $3 \times 5$, composto por três resíduos e cinco doses de cada resíduo $\left(0\right.$ tha $^{-1}, 1$ tha $^{-1}, 2$ tha $^{-1}, 4$ tha $^{-1}$ e 8 tha $\left.^{-1}\right)$, as quais correspondem às doses de $0 \mathrm{~g} ; 2,5 \mathrm{~g} ; 5 \mathrm{~g} ; 10 \mathrm{~g}$; e $20 \mathrm{~g}$ por vaso. Neste experimento, buscou-se obter a maior produtividade e o menor risco ambiental, com o maior uso de resíduos, o que explica a escolha das doses em estudo. Como referência, foi utilizada uma amostra de solo sem adubo e sem resíduo (D0T). A amostra de dose $0 \mathrm{t} \mathrm{ha}^{-1}$, muitas vezes, é mencionada como D0C, por ter recebido adubação e fazer parte dos tratamentos em estudo.

O solo foi seco ao ar, à temperatura ambiente $\left(25 \pm 5^{\circ} \mathrm{C}\right)$, e, em seguida, passado através de peneira de malha com $2 \mathrm{~mm}$ de diâmetro de abertura. Cada resíduo foi misturado de forma homogênea ao solo, juntamente com adubação (usando reagentes PA) suficiente para garantir a produtividade das culturas. Para o primeiro cultivo, fez-se a adubação com solução contendo $\mathrm{N}, \mathrm{K}, \mathrm{Ca}, \mathrm{Mg}, \mathrm{S}, \mathrm{B}, \mathrm{Cu}, \mathrm{Zn}$ e Mo
(300 mg kg-1; $350 \mathrm{mg} \mathrm{kg}^{-1} ; 80 \mathrm{mg} \mathrm{kg}^{-1} ; 30 \mathrm{mg} \mathrm{kg}^{-1}$; $50 \mathrm{mg} \mathrm{kg}^{-1} ; 0,5 \mathrm{mg} \mathrm{kg}^{-1} ; 1,5 \mathrm{mg} \mathrm{kg}^{-1} ; 5 \mathrm{mg} \mathrm{kg}^{-1}$; $\mathrm{e}$ $0,1 \mathrm{mg} \mathrm{kg}^{-1}$, respectivamente), enquanto, para o segundo cultivo, a suplementação nutricional incluiu $\mathrm{N}, \mathrm{P}, \mathrm{K}, \mathrm{Mg}, \mathrm{S}, \mathrm{B}, \mathrm{Cu}$ e $\mathrm{Zn}$, nas concentrações de $200 \mathrm{mg} \mathrm{kg}^{-1} ; 150 \mathrm{mg} \mathrm{kg}^{-1} ; 160 \mathrm{mg} \mathrm{kg}^{-1} ; 20 \mathrm{mg} \mathrm{kg}^{-1}$; $40 \mathrm{mg} \mathrm{kg}^{-1} ; 0,25 \mathrm{mg} \mathrm{kg}^{-1} ; 0,75 \mathrm{mg} \mathrm{kg}^{-1}$; e 2,5 $\mathrm{mg} \mathrm{kg}^{-1}$, respectivamente.

Em cada vaso, foram acondicionados $5 \mathrm{~kg}$ de solo, quantidade calculada para produzir uma coluna de $0,25 \mathrm{~m}$ de diâmetro por $0,20 \mathrm{~m}$ de altura, aproximadamente. A parte inferior interna dos vasos continha um orifício conectado a uma mangueira flexível, para permitir a saída dos lixiviados para os frascos coletores. Tal orifício foi protegido por uma camada de "lã de vidro", para impedir a passagem de partículas de solo e evitar o entupimento do mesmo.

Foram realizados dois cultivos, a fim de verificar a disponibilidade de metais pesados às plantas, sendo o primeiro com capim-elefante (Penissetum purpureum Schum.) cv. Napier, por 120 dias, e, o segundo, com feijão (Phaseolus vulgaris Lineau) cv. Talismã, por 75 dias. Após o primeiro cultivo (capim-elefante), as raízes foram retiradas do solo e realizou-se a correção do mesmo (adição de $\mathrm{CaCO}_{3}$ equivalente a $1,35 \mathrm{t} \mathrm{ha}^{-1}$ ), para elevar a saturação de bases a $70 \%$. Estas culturas foram escolhidas por serem tradicionais e importantes, socioeconomicamente, não só na região de Juiz de Fora (MG), mas em todo o Brasil. Os dados referentes à absorção de nutrientes foram discutidos por Nascimento (2005).

A umidade dos vasos foi mantida a $70 \%$ da capacidade de campo, por meio da adição diária de água deionizada. $\mathrm{O}$ registro do volume de água lixiviada foi feito diariamente. No entanto, este volume era alterado, em função da temperatura ambiente, e, durante dois dias da semana, esta quantidade era dobrada, para garantir a lixiviação, coleta e análise dos teores de $\mathrm{Pb}$ e $\mathrm{Zn}$, as quais foram realizadas durante cerca de 200 dias, para verificar uma possível movimentação de $\mathrm{Pb}$ e Zn. Tais análises foram feitas em espectrofotômetro de absorção atômica, com chama de ar-acetileno.

Tabela 2. Caracterização química ${ }^{1}$ dos resíduos siderúrgicos utilizados no estudo (Lavras, MG, 2003).

\begin{tabular}{lrrrrrrrrrrrrrr}
\hline \multicolumn{1}{c}{ Resíduos } & $\mathrm{pH}$ & $\mathrm{P}$ & $\mathrm{K}$ & $\mathrm{Ca}$ & $\mathrm{Mg}$ & $\mathrm{S}$ & $\mathrm{Na}$ & $\mathrm{Zn}$ & $\mathrm{Ni}$ & $\mathrm{Cr}$ & $\mathrm{Pb}$ & $\mathrm{Cd}$ & $\mathrm{Mn}$ & $\mathrm{Fe}$ \\
\hline
\end{tabular}


Devido às variações nos volumes de água deionizada adicionados aos vasos, todos os cálculos dos teores de $\mathrm{Zn} \mathrm{e} \mathrm{Pb}$ foram feitos em função do volume de poros. Este volume foi calculado pela razão entre o volume de água lixiviado e o volume de água adicionado a cada vaso. O volume de poros, portanto, é uma grandeza adimensional.

Os dados foram submetidos a análise descritiva, com cálculo das médias para as três repetições, avaliando-se os teores de $\mathrm{Zn}$ e $\mathrm{Pb}$ lixiviados.

\section{RESULTADOS E DISCUSSÃO}

A aplicação de doses da carepa de aciaria, lama de filtro-prensa e lama de fosfato não influenciou os teores de $\mathrm{Pb}$, na água do lixiviado. A concentração de $\mathrm{Pb}$ no lixiviado foi semelhante à das testemunhas. Nota-se, porém, que, até mesmo as testemunhas, que não receberam aplicação de resíduos, apresentaram, em certas ocasiões, teores de $\mathrm{Pb}$ acima do permitido pela legislação (Figura 1). Como não existe legislação específica para lixiviados, utilizou-se a resolução da Cetesb (2005), que é destinada ao estabelecimento de valores orientadores para águas subterrâneas.

Observa-se que, de acordo com a legislação, os teores de $\mathrm{Pb}$ encontrados no lixiviado estiveram sempre acima do valor máximo permitido para este elemento em águas subterrâneas $\left(0,010 \mathrm{mg} \mathrm{L}^{-1}\right)$. Porém, isto foi verificado em condições de casa-de-vegetação, com ambiente bastante restrito, em uma coluna de solo de apenas $0,20 \mathrm{~m}$ de altura. Caso tal situação ocorresse em condições de campo, este risco, provavelmente,

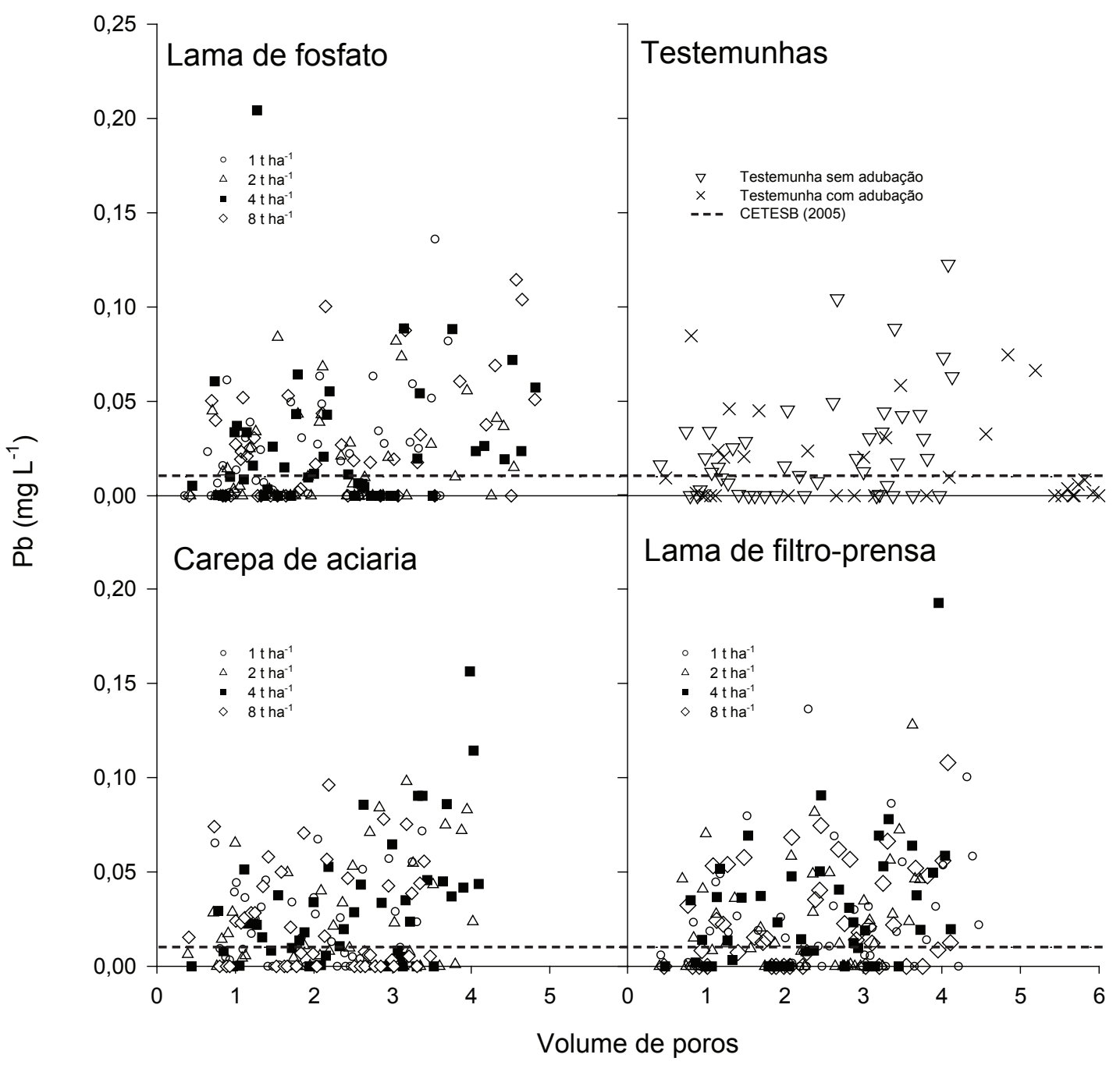

Figura 1. Teores de $\mathrm{Pb}$ na água lixiviada $(\mathrm{n}=3)$, em solo tratado com doses de carepa de aciaria, lama de filtro-prensa e lama de fosfato e em solos sem resíduo (testemunha sem adubação (D0T) e com adubação (D0C)). A linha tracejada refere-se à decisão de diretoria da Cetesb (2005) (Lavras, MG, 2003/2004). 
não existiria, pois, geralmente, Latossolos apresentam mais de $20 \mathrm{~m}$ de profundidade entre a superfície do solo e o lençol freático (Resende et al. 2002).

Na figura 2, é possível verificar que, para o Zn, o aumento das doses da lama de fosfato influenciou os teores deste elemento no lixiviado, aumentando a quantidade total de $\mathrm{Zn}$ lixiviada por vaso, em razão das doses de resíduo aplicadas (Figura 2). Observa-se, ainda, na figura 2, que a lixiviação de $\mathrm{Zn}$, devido à aplicação da carepa de aciaria e da lama de filtro-prensa, atingiu magnitude semelhante à das testemunhas.

A elevada concentração de $\mathrm{Zn}$ presente na lama de fosfato adicionada ao solo, associada às características deste elemento, foram responsáveis por sua intensa lixiviação, a qual, também, pode ter sido favorecida pela acidez do solo $(\mathrm{pH}=5,9)$, o que estimularia a ocorrência deste metal em formas trocáveis e solúveis. De maneira geral, a elevação das doses da lama de fosfato aumentou, significativamente, a concentração de Zn na massa seca da parte aérea do capim-elefante e do feijão, o que valida o aumento da disponibilidade de $\mathrm{Zn}$ para a solução do solo.

A mobilidade de $\mathrm{Zn}$ está relacionada à sua presença no solo, predominantemente em formas trocáveis, e, portanto, facilmente solúveis (Kabata-Pendias \& Adriano1995, Amaral Sobrinho et al. 1998). Por sua vez, tais frações estão estreitamente associadas à contaminação do lençol freático e de plantas. Embora a aplicação de lama de fosfato e filtro-prensa, ambas com elevados teores de Zn, não tenha provocado sintomas de toxidez na parte aérea e

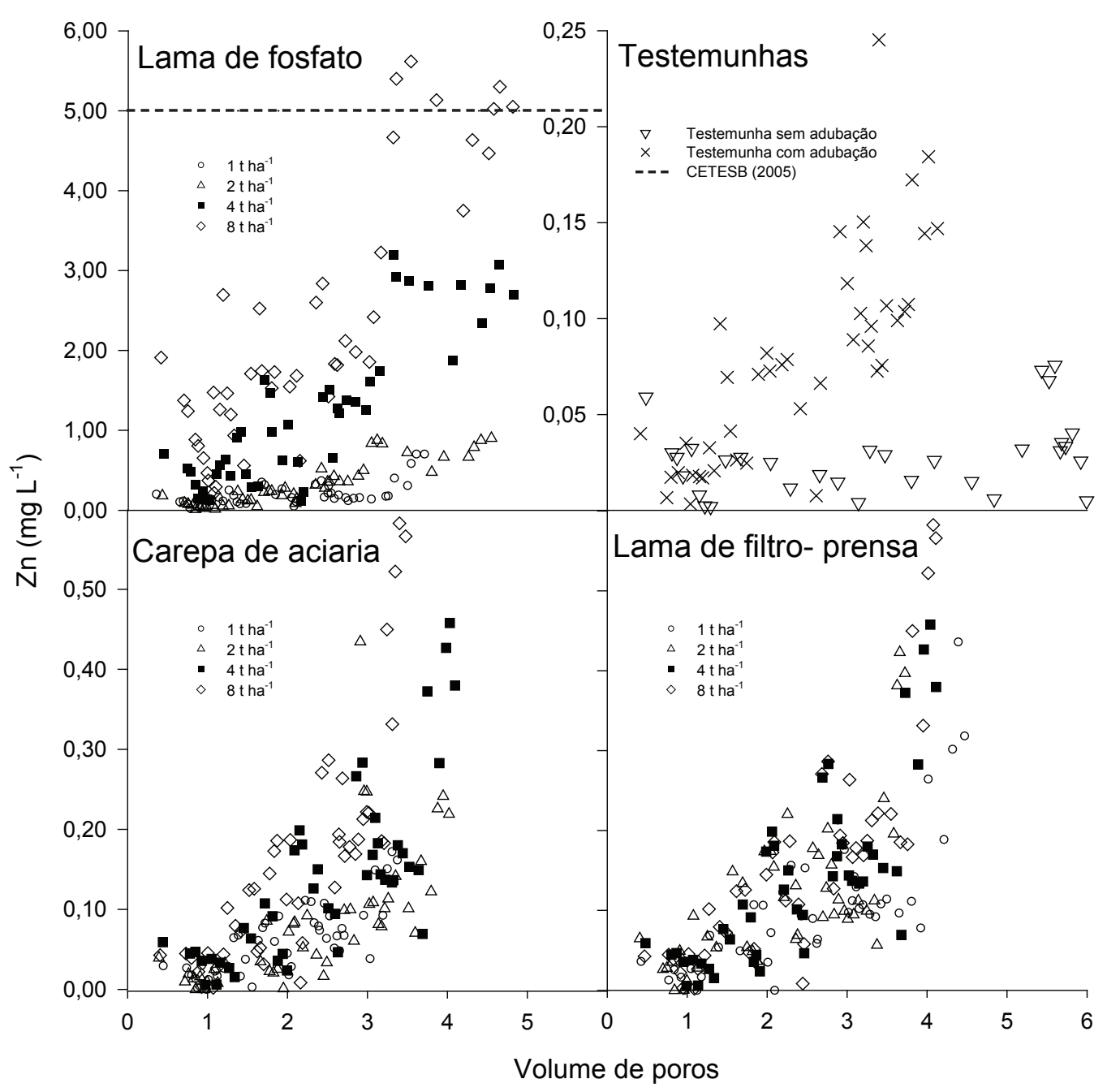

Figura 2. Teores de Zn na água lixiviada $(n=3)$, em solo tratado com doses de carepa de aciaria, lama de filtro-prensa e lama de fosfato e em solos sem resíduo (testemunha sem adubação (D0T) e com adubação (D0C)). A linha tracejada refere-se à decisão de diretoria da Cetesb (2005) (Lavras, MG, 2003/2004). 
na raiz do capim-elefante, o feijão produzido nos solos submetidos a doses crescentes de lama de fosfato apresentaram sintomas de toxidez por este elemento. Foram observadas reduções no crescimento da planta e no tamanho do folíolo, que se iniciou ao décimo dia após o plantio. As folhas ficaram esverdeadas, com aspecto coriáceo e encarquilhadas, apresentando nervuras abaxiais arroxeadas. Estas plantas demoraram a emitir o botão floral, o que ocasionou redução drástica na produção de vagens e grãos. Para a dose de $4 \mathrm{t} \mathrm{ha}^{-1}$, não houve produção de grãos. Estes sintomas não podem estar associados aos efeitos diretos provocados pelo $\mathrm{Zn}$, pois o excesso deste elemento causa graves distúrbios nutricionais em plantas, impedindo seu desenvolvimento (Soares et al. 2001), inclusive o do sistema radicular.

Não foram observados efeitos tóxicos de $\mathrm{Pb}$, nas plantas de capim-elefante e feijão, com o aumento das doses dos resíduos de siderurgia. Entretanto, o aumento das doses dos resíduos aumentou os teores $\mathrm{de} \mathrm{Pb}$ no capim-elefante, enquanto, para o feijão, o aumento das doses da lama de filtro-prensa ocasionou o aumento dos teores de $\mathrm{Pb}$, na folha e na vagem, até a dose de $4 \mathrm{t} \mathrm{ha}^{-1}$ do resíduo. A lama de fosfato aumentou, linearmente, o teor $\mathrm{de} \mathrm{Pb}$ apenas na folha, enquanto a carepa de aciaria, além de aumentar o teor deste elemento na vagem, foi o único resíduo que aumentou o teor de $\mathrm{Pb}$ também no grão.

A baixa mobilidade de $\mathrm{Pb}$, nas colunas de solo estudadas, pode ser explicada devido aos processos de adsorção, que são os mais importantes no controle da mobilidade e biodisponibilidade de metais em solos (Alloway 1990, Sparks 1995). A elevada associação do $\mathrm{Pb}$ com o grupo funcional $\mathrm{OH}^{-}$(hidroxila), presente na superfície da caulinita, óxidos, oxihidróxidos e hidróxidos de Fe e Al, pela adsorção específica, foi relatada por Sheppard \& Sheppard (1991), Amaral Sobrinho et al. (1997, 1998), Mazur (1997) e Araújo et al. (2000). A adsorção específica deste metal, pela troca de ligantes ou ligações covalentes com a fase sólida do solo, resulta na formação de moléculas bastante estáveis, com alto poder de energia, também chamadas de complexos de esfera interna. Este mecanismo de ligação é, geralmente, irreversível e fracamente afetado pela força iônica da solução (Sparks 1995). Estas características conferem ao $\mathrm{Pb}$ baixa mobilidade e baixa biodisponibilidade em solos intemperizados (Amaral Sobrinho et al. 1998, 1999).
A baixa mobilidade do $\mathrm{Pb}$ e a consequente acumulação nos horizontes superficiais foram verificadas em diversos estudos (Biddappa et al. 1982, Sheppard \& Sheppard 1991). Kabata-Pendias \& Pendias (2001) atribuíram tal situação à elevada capacidade de complexação do $\mathrm{Pb}$ à matéria orgânica. Clevenger (1990) atribuiu-a ao acúmulo deste metal na fração residual e Sheppard \& Thibault (1992) à alta afinidade do $\mathrm{Pb}$ pelos óxidos de $\mathrm{Fe}$ e $\mathrm{Mn}$. Isto é compatível com o comportamento típico deste elemento, observado em solos contaminados, isto é, alta retenção (Elliott et al. 1986), baixa mobilidade (Amaral Sobrinho et al. 1998) e baixa disponibilidade (Alloway 1990).

Quanto à alta mobilidade de $\mathrm{Zn}, \mathrm{McBride}$ (1994) sugere que a adsorção não específica, pela formação de complexos de esfera externa, de menor estabilidade, exerce papel importante na retenção deste metal no solo estudado. A adsorção mais fraca deste elemento, em comparação ao $\mathrm{Pb}$ e $\mathrm{Cu}$, explica a maior mobilidade e biodisponiblidade deste metal, verificadas em alguns trabalhos (Amaral Sobrinho et al. 1998, 1999), inclusive neste.

De acordo com os valores orientadores (Cetesb 2005), o limite máximo aceitável de $\mathrm{Zn}$ em águas subterrâneas é de $5 \mathrm{mg} \mathrm{L}^{-1}$. Nas doses de $1 \mathrm{t} \mathrm{ha}^{-1}$, $2 \mathrm{t} \mathrm{ha} \mathrm{a}^{-1} \mathrm{e} 4 \mathrm{t} \mathrm{ha}^{-1}$ da lama de fosfato, os teores de $\mathrm{Zn}$ encontrados na água do lixiviado estiveram sempre abaixo deste limite. No entanto, o limite tendeu a ser ultrapassado na dose de $8 \mathrm{t} \mathrm{ha}^{-1}$, próximo ao quarto volume de poros, verificando-se pico máximo de $5,3 \mathrm{mg} \mathrm{L}^{-1}$. Tal fato limita a utilização de doses elevadas deste resíduo na agricultura.

\section{CONCLUSÕES}

1. Mesmo com aplicações excessivas de lama de fosfato, carepa de aciaria e lama de filtro-prensa, não houve mobilidade de $\mathrm{Pb}$ na coluna de solo.

2. O Zn proveniente da lama de fosfato possui elevada mobilidade na coluna de solo.

3. A lama de fosfato, aplicada em doses acima ou próximas a $8 \mathrm{t} \mathrm{ha}^{-1}$, pode, eventualmente, vir a contaminar o lençol freático, devido aos altos teores de $\mathrm{Zn}$, particularmente em perfis de solo mais rasos e após várias aplicações deste resíduo.

4. Dos resíduos estudados, a carepa de aciaria e a lama de filtro-prensa não resultaram na movimentação $\mathrm{de} \mathrm{Pb}$ e $\mathrm{Zn}$. Portanto, estes dois resíduos devem ser mais detalhadamente estudados, em experimentos de campo. 


\section{AGRADECIMENTOS}

À Fundação de Amparo à Pesquisa do Estado de Minas Gerais (Fapemig), pelo financiamento do projeto e concessão de bolsas de pós-graduação.

\section{REFERÊNCIAS}

ALLOWAY, B. J. Cadmium. In: ALLOWAY, B. J. (Ed.). Heavy metals in soils. New York: J. Willey, 1990. p. 100121.

AMARAL SOBRINHO, N. M. B.; VELLOSO, A. C. X.; COSTA, L. M. Lixiviação de $\mathrm{Pb}, \mathrm{Zn}, \mathrm{Cd}$ e Ni em solo Podzólico Vermelho-Amarelo tratado com resíduos siderúrgicos. Floresta e Ambiente, Seropédica, v. 6, n. 1, p. 65-75, 1999.

AMARAL SOBRINHO, N. M. B; VELLOSO, A. C. X.; OLIVEIRA, C. Solubilidade de metais pesados em solo tratado com resíduo siderúrgico. Revista Brasileira de Ciência do Solo, Viçosa, v. 21, n. 1, p. 9-16, 1997.

AMARAL SOBRINHO, N. M. B. et al. Mobilidade de metais pesados em solo tratado com resíduo siderúrgico. Revista Brasileira de Ciência do Solo, Viçosa, v. 22, n. 2, p. 345-353, 1998.

ARAÚJO, W. S.; AMARAL SOBRINHO, N. M. B. Influência das propriedades físicas e químicas de solos intemperizados na adsorção de chumbo, cobre e zinco. Floresta e Ambiente, Seropédica, v. 7, n. 1, p. 167-180, 2000.

BIDDAPPA, C. C.; CHINO, M.; KUMAZAWA, K. Migration of heavy metals in two Japanese soils. Plant Soil, Dordrecht, v. 66, n. 3, p. 299-316, 1982.

CLEVENGER, T. E. Use of sequential extraction to evaluate the heavy metals in mining wastes. Water, Air, and Soil Pollution, Dordrecht, v. 50, n. 3/4, p. 241-254, 1990.

COMPANHIA DE TECNOLOGIA DE SANEAMENTO AMBIENTAL (Cetesb). Decisão de Diretoria n. 1952005-E. 2005. Disponível em: <http://www.cetesb.sp.gov. $\mathrm{br} / \mathrm{Solo} /$ relatorios/tabela_valores_2005.pdf $>$. Acesso em: 12 dez. 2005.

CUNHA, A. F. et al. Caracterização, beneficiamento e reciclagem de carepas geradas em processos siderúrgicos. Revista Escola de Minas, Ouro Preto, v. 59, n. 1, p. 111116, 2006.

DE FILIPPO, B.; RIBEIRO, A. C. Análise química do solo: metodologia. 2. ed. Viçosa: UFV, 1997.
ELliot, H. A.; LIBERATI, M. R.; HUANG, C. P. Competitive adsorption of heavy metals by soils. Journal of Environmental Quality, Madison, v. 15, n. 3, p. 214217, 1986.

EMPRESA BRASILEIRA DE PESQUISA AGROPECUÁRIA (Embrapa). Manual de métodos de análise de solo. Brasília, DF: Embrapa Comunicação para Transferência de Tecnologia, 1997.

HAYES, K. F.; TRAINA, S. J. Metal speciation and its significance in ecosystem health. In: HUANG, P. M. (Ed.). Soil chemistry and ecosystem health. Madison: Soil Science of America, 1998. p. 45-84.

KABATA-PENDIAS, A.; ADRIANO, D. C. Trace metals. In: RECHCIGL, J. E. (Ed.). Soil amendments and environmental quality. Boca Raton: Lewis, 1995. p. $139-167$

KABATA-PENDIAS, A.; PENDIAS, H. Trace elements in soils and plants. 3. ed. Boca Raton: CRC Press, 2001.

MAEDA, S.; MIZOGUCHI, M.; OHKI,A. Bioaccumulation of zinc and cadmium in freshwater alga, Chlorella vulgaris: Part I. Toxicity and accumulation. Chemosphere, Oxford, v. 21, n. 8, p. 953-963, 1990.

MALAVOLTA, E.; VITTI, G. C.; OLIVEIRA, A. S. Avaliação do estado nutricional das plantas: princípios e aplicações. Piracicaba: Associação Brasileira para Pesquisa da Potassa e do Fosfato, 1989.

MAZUR, N. Biossignificância de níquel, chumbo, zinco e cobre em solos que receberam composto de resíduo sólido urbano. 1997. 135 f. Tese (Doutorado em solos e Nutrição de Plantas)-Universidade Federal de Viçosa, Viçosa, 1997.

McBRIDE, M. B. Environmental chemistry of soils. New York: Oxford University Press, 1994.

NASCIMENTO, R. S. M. P. Uso agrícola de resíduos de siderurgia: avaliação de extratores, crescimento vegetal e lixiviação de metais pesados. 2005. 109 f. Dissertação (Mestrado em Solos e Nutrição de Plantas)-Universidade Federal de Lavras, Lavras, 2005.

OLIVEIRA, F. C. et al. Movimentação de metais pesados em Latossolo adubado com composto de lixo urbano. Pesquisa Agropecuária Brasileira, Brasília, DF, v. 37, n. 12, p. 1787-1793, 2002.

PRADO, R. M.; FERNANDES, F. M.; NATALE, W. Uso agrícola da escória de siderurgia do Brasil: estudos na cultura da cana-de-açúcar. Jaboticabal: Funep, 2001.

PRADO, R. M. et al. Avaliação da escória de siderurgia e de calcários como corretivos da acidez do solo no cultivo da alface. Pesquisa Agropecuária Brasileira, Brasília, DF, v. 37, n. 4, p. 539-546, 2002. 
RESENDE, M. et al. Pedologia: base para distinção de ambientes. 4. ed. Viçosa: Neput, 2002.

SHEPPARD, S. C.; SHEPPARD, M. I. Lead in boreal soils. Water, Air, and Soil Pollution, Dordrecht, v. 58, n. 1, p. 79-91, 1991.

SHEPPARD, M. I.; THIBAULT, D. H. Desorption and extraction of selected heavy metals from soils. Soil Science Society of America Journal, Madison, v. 56, n. 2, p. 415423, 1992.

SOARES, C. R. F. S. et al. Acúmulo e distribuição de metais pesados nas raízes, caule e folhas de mudas de árvores de solo contaminado por rejeitos de indústria de zinco. Revista Brasileira de Fisiologia Vegetal, Brasília, DF, v. 13, n. 3, p. 302-315, 2001.
SPARKS, D. L. Environmental soil chemistry. San Diego: Academic Press, 1995.

UNITED STATES ENVIRONMENTAL PROTECTION AGENCY (USEPA). Method 3051 A: micro-wave assisted acid digestion of sediments sludge, soils and oils. In: SW-846: test methods for evaluation of solid waste physical and chemical methods, Office of Solid Waste, US. Washington, DC: USEPA, 1998. p. 1-20. 